\section{Failed spinal anaesthesia: cause identified by MRI}

Yoshihiro Hirabayashi MD, Hirokazu Fukuda MD, Kazuhiko Saitoh MD, Soichiro Inoue MD, Hiromasa Mitsuhata MD, Reiju Shimizu MD
Purpose: To determine the cause of failed spinal anaesthesia, magnetic resonance images of the lumbar spine were examined.

Clinical futures: A 28-yr-old woman, scheduled for closure of a rectal fistula under spinal anaesthesia, hyperbaric tetracaine $12.5 \mathrm{mg}$ injected into the subarachnoid space at $L_{3-4}$ repeatedly resulted in restricted sacral spread. Magnetic resonance imaging showed that the cylindrical dimension of the lumbar spinal canal was wider than in normal subjects, suggesting a larger volume of CSF within the dural sac below the termination of the cord. The summit of the lumbar convexity was located at $L_{3}$, which was more cephalad than the $L_{3-4}$ puncture site.

Conclusion: The uncommon anatomical characteristics of the lumbar spinal canal identified by magnetic resonance imaging were considered to be the reason for the restricted sacral spread observed repeatedly in this patient.

Objectif: Déterminer à l'aide de l'imagerie par résonance magnétique (IRM) les causes de l'échec d'une rachianesthésie.

Caractéristiques cliniques: Chez une femme de 28 ans programmée pour une fermeture de fistule rectale sous rachianesthésie, l'injection répétée de $12,5 \mathrm{mg}$ de tétracaïne hyperbare dans l'espace sous-archnoïdien à $L_{3-4}$ a produit une analgésie limitée à la région sacrée. L'IRM a révélé que la dimension cyclindrique du canal rachidien lombaire était plus grande que la normale, suggérant que le sac dural contenait aussi un plus grand volume de LCR. Le sommet de la con-

\section{Key words}

ANAESTHETIC TECHNIQUES: spinal;

MEASUREMENT TECHNIQUES: magnetic resonance imaging.

From the Department of Anesthesiology, Jichi Medical School, Tochigi 329-04, Japan.

Address correspondence to: Dr. Yoshihiro Hirabayashi, Department of Anesthesiology, Jichi Medical School,

Tochigi 329-04, Japan.

Phone: +8128544 2111. Fax: +81285444108 .

Accepted for publication May 24, 1996. vexité lombaire était situé à $L_{3}$, niveau plus élevé que le site de ponction $L_{3-4}$.

Conclusion: Les caractéristiques anatomiques inhabituelles du canal rachidien lombaire identifiées par IRM ont été considérées comme la cause de la restriction à la région sacrée de l'analgésie observée à plusieurs reprises chez cette patiente.

Spinal anaesthesia with hyperbaric local anaesthetic is one of the most reliable of anaesthetic techniques in clinical practice. Once hyperbaric local anaesthetics are deposited in the mid-lumbar subarachnoid space, an adequate block is expected. However, failed spinal anaesthesia rarely occurs after an uneventful spinal injection. ${ }^{1-3}$ We encountered a case in which an uneventful spinal injection repeatedly resulted in restricted sacral spread. Magnetic resonance imaging (MRI) of the lumbar spine showed uncommon anatomical characteristics of the spinal canal, which were considered to be the reason for the restricted sacral spread.

\section{Case report}

A 28-yr-old woman was admitted for closure of a rectal fistula. She had suffered from ulcerative colitis since the age of $14 \mathrm{yr}$. Surgical history included total colectomy with general anaesthesia at the age of $27 \mathrm{yr}$. She was $159 \mathrm{~cm}$ in height and weighed $40 \mathrm{~kg}$.

The patient received premedication with $0.3 \mathrm{mg}$ scopolamine and $50 \mathrm{mg}$ hydroxyzine $\mathrm{im}$. After arrival in the operating room, intravenous access was established. She was positioned in the lateral position on a horizontal operating table. Under aseptic condition, a 25 gauge Quincke needle was inserted into the subarachnoid space at the $\mathrm{L}_{3-4}$ interspace. The needle was inserted with its bevel oriented parallel to the dural fibres and then rotated $90^{\circ}$ to direct the bevel cephalad. Tetracaine $12.5 \mathrm{mg}$ in $2.5 \mathrm{ml}$, glucose $10 \%$ solution (Tetcaine ${ }^{\circledR}$ for injection $20 \mathrm{mg}$ (crystalline preparation), Kyorin Pharmaceutical Co., Ltd., Tokyo, Japan) was injected through the needle over $25 \mathrm{sec}$, and the correct position of the needle was confirmed by aspiration and reinjection of clear cerebrospinal fluid (CSF) immediately 
before and after the injection. After the subarachnoid injection was performed, the patient was gently turned to the supine position on a horizontal operating table. Because sensory analgesia to pin-prick had reached only $\mathrm{L}_{5}, 20 \mathrm{~min}$ after the spinal injection, the lumbar puncture was repeated. The same quantity of hyperbaric tetracaine was injected into the subarachnoid space over $25 \mathrm{sec}$ through a 25 gauge Quincke needle inserted at the $\mathrm{L}_{2-3}$ interspace with the patient in the lateral position. The patient was placed on Tredelenburg position for $15 \mathrm{~min}$. Sensory analgesia to pin-prick reached $\mathrm{T}_{4}$ at $15 \mathrm{~min}$ after the second spinal injection. The closure of the rectal fistula took $30 \mathrm{~min}$. Two months later, the patient was scheduled on a closure of a residual rectal fistula under spinal anaesthesia. No premedication was given. She was positioned in the lateral position on a horizontal operating table. Tetracaine $12.5 \mathrm{mg}$ in $2.5 \mathrm{ml}$, $10 \%$ glucose solution was injected over $25 \mathrm{sec}$ through a 25 gauge Quincke needle inserted into the subarachnoid space at the $\mathrm{L}_{3-4}$ interspace in the lateral position on a horizontal operating table. Although deposit of the entire spinal dose in the subarachnoid space was confirmed by aspiration and reinjection of clear CSF immediately before and after the injection, sensory analgesia to pin-prick was $\mathrm{L}_{5}$ at $20 \mathrm{~min}$ after the spinal injection. We decided to repeat lumbar puncture. Tetracaine 10 $\mathrm{mg}$ in $2 \mathrm{ml}, 10 \%$ glucose solution was injected into the subarachnoid space over $20 \mathrm{sec}$ through a 25 gauge Quincke needle at the $\mathrm{L}_{2-3}$ interspace with the patient in the lateral position. Then, the patient was placed in the Tredelenburg position. Sensory analgesia to pin-prick reached $T_{7}$ at $15 \mathrm{~min}$ after the second spinal injection. The rectal fistula was repaired in $65 \mathrm{~min}$.

\section{MRI findings}

To determine the reason for the restricted sacral spread, MRI examination of the lumbar spine was performed on the 7 th postoperative day. $T_{1}$-weighted sagittal and axial images were obtained by the MRI scanner (MRT200/FXIII super version, Toshiba Corporation, Tokyo, Japan) operating at $1.5 \mathrm{~T}$ with a single surface coil. The area within the dural sac on the axial image at the level of the third lumbar vertebra was $2.8 \mathrm{~cm}^{2}$ (Figure C). The highest point of the lumbar spinal canal was found to be located at $\mathrm{L}_{3}$ (Figure $\mathrm{A}$ ).

To compare these findings with those in the normal dural sac in young women, MRI examination was also performed in 13 Japanese healthy female volunteers (age $26 \pm 4$ yr [range $20-31 \mathrm{yr}$ ], mean $\pm \mathrm{SD}$; height 160 $\pm 4 \mathrm{~cm}$ [range 154-160 cm]; and weight $52 \pm 4 \mathrm{~kg}$ [range $43-57 \mathrm{~kg}$ ]). The area within the dural sac on the axial image at the level of the third lumbar vertebra was
$1.64 \pm 0.33 \mathrm{~cm}^{2}$ [range $1.3-2.3 \mathrm{~cm}^{2}$ ]. The cylindrical dimension of the patient was wider than in controls, suggesting a large volume of CSF within the dural sac.

\section{Discussion}

Hyperbaric tetracaine $12.5 \mathrm{mg}$ injected into the subarachnoid space at the $\mathbf{L}_{3-4}$ interspace repeatedly resulted in an unusually low level of block. However, injection of the same dose at the $\mathrm{L}_{2-3}$ interspace led to a successful block. Magnetic resonance imaging (MRI) of the lumbar spine showed uncommon anatomical characteristics of the spinal canal, which consisted of a wider cylindrical dimension and a cephalad positioned summit of the lumbar convexity.

There are several possible causes for restricted spread. Some or all of the anaesthetic solution may not have been introduced into the subarachnoid space. In this case, clear CSF flow was present immediately before and after injection of the anaesthetic solution and, hence, the entire spinal dose seems to have been deposited in the subarachnoid space. There may have been an error with respect to dose and positioning of the patient. ${ }^{3}$ However, we used $12.5 \mathrm{mg}$ hyperbaric tetracaine with the patient in the lateral position on a horizontal operating table. Usually, $12.5 \mathrm{mg}$ hyperbaric tetracaine $0.5 \%$ administered with patients in the lateral position results in a mid-thoracic block. ${ }^{4}$ Tetracaine 12.5 $\mathrm{mg}$ is considered to be an adequate dose for a $40 \mathrm{~kg}, 149$ $\mathrm{cm}$ adult woman. The local anaesthetic may have been past its expiration date. ${ }^{5}$ However, repeated injection of the same drug led to an adequate block, so that this was not the cause.

The volume of CSF below the termination of the cord may affect the distribution of local anaesthetics within the subarachnoid space. A dose of local anaesthetic injected into an increased volume of spinal CSF may lead to reduced spread of local anaesthetic. ${ }^{6}$ In addition, since hyperbaric anaesthetic solutions injected into the subarachnoid space migrate in both cephalad and caudal directions under the influence of gravity, the anatomical configuration of the lumbar spine in the supine position plays an important role in determining the distribution of anaesthetic. We suggest, in this patient, these two anatomical characteristics of the lumbar spine may have been related to the restricted spread.

In this patient, sagittal and axial MRI of the lumbar spine revealed a very large cylindrical dimension of the spinal canal. The area within the dural sac at the level of the third lumbar vertebra was $2.8 \mathrm{~cm}^{2}$. This exceeds values that we found in young female Japanese volunteers $\left(1.64 \pm 0.33 \mathrm{~cm}^{2}\right)$. This may result a large volume of CSF below the termination of the spinal cord, and prob- 

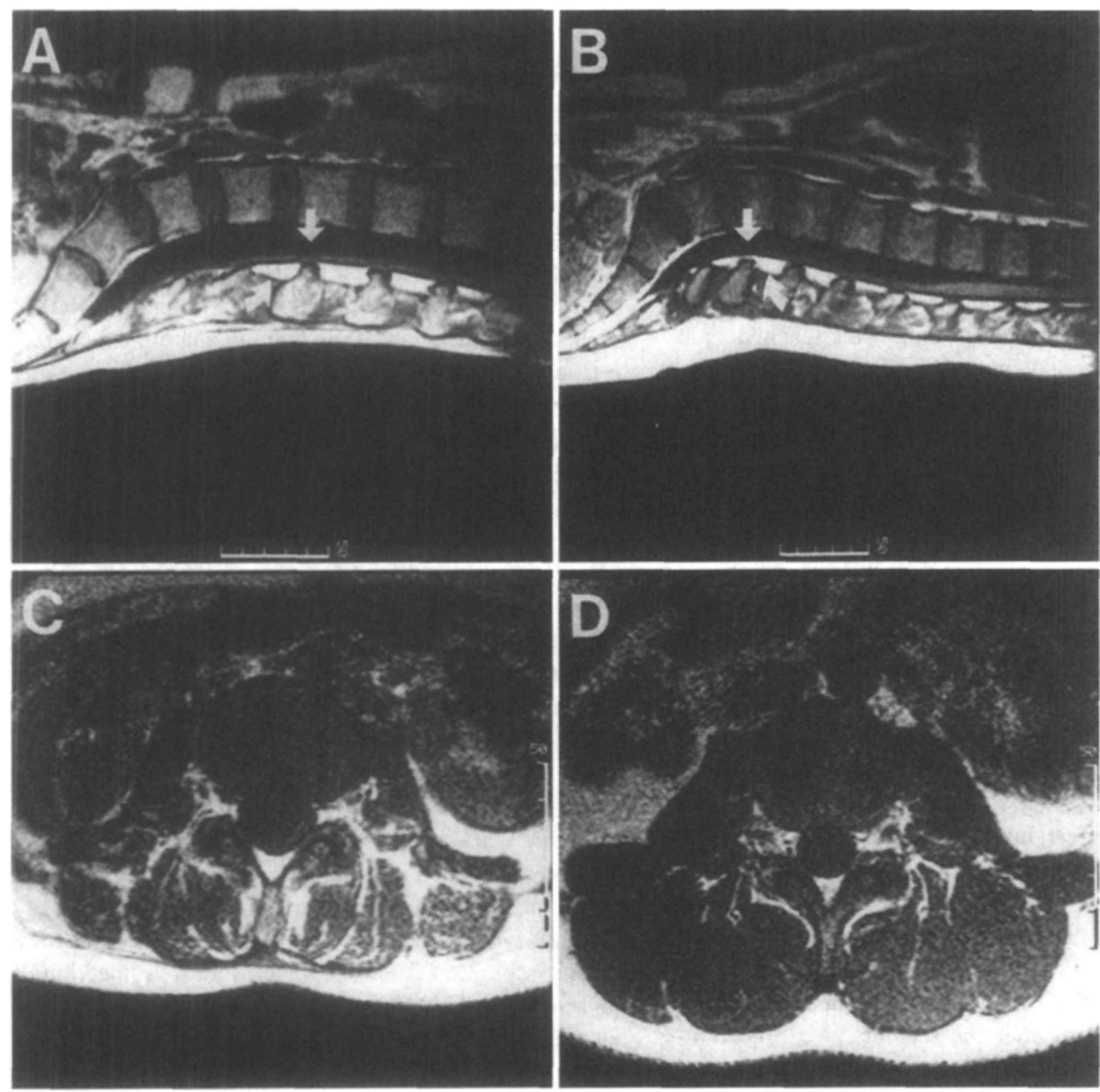

FIGURE $\mathrm{T}_{1}$-weighted mid-line sagittal MR images of the lumbar spine in the patient (A) and a healthy female volunteer (age $26 \mathrm{yr}$, weight $54 \mathrm{~kg}$ and $154 \mathrm{~cm}$ in height) (B); and $T_{1}$-weighted axial MR images at the level of intervertebral foramina of the third lumbar vertebra in the patient (C) and the same volunteer (D). A straight arrow indicates the summit of the lumbar convexity, which is positioned at $L_{3}$ in the patient $(A)$ and at $L_{4}$ in the volunteer (B). A curved arrow shows the $\mathrm{L}_{3-4}$ interspace, which is located on the down-slope in the caudal direction in the patient $(A)$ and on the down-slope in the cephalic direction in the volunteer (B). The area within the dural sac is larger in the patient (C) than in the volunteer (D), being $2.8 \mathrm{~cm}^{2}$ in the former and $1.8 \mathrm{~cm}^{2}$ in the latter.

ably led to the restricted sacral spread. However, no studies exist demonstrating variations of size of the normal dural sac determined from MRI. Because the number of the volunteers in the control group was small, our conclusion should be interpreted with caution. In order to advance our understanding of the role of size of the dural sac in failed spinal anaesthetic, large populations including spinal patients with canal stenosis should be studied. Nevertheless, our MRI examination provided a possible explanation for the failed spinal anaesthetic. In addition, in this patient, the summit of the lumbar con- vexity, that is usually at $\mathrm{L}_{4}$ in the supine position, was found to be located at $\mathrm{L}_{3}$. Thus, the $\mathrm{L}_{3-4}$ interspace was more caudad than the summit of the lumbar convexity (Figure) and this might have increased the amount of hyperbaric tetracaine moving caudally. Lumbar puncture performed at the $\mathrm{L}_{3-4}$ interspace resulted in restricted sacral spread, whereas injection of the same dose at $\mathrm{L}_{2-3}$ led to a successful block.

The incidence of failure to achieve satisfactory spinal anaesthesia varies from $3-14 \% .^{1-3}$ Causes include a lack of free flow of CSF, the use of tetracaine without epi- 
nephrine, ${ }^{1,3}$ and errors in judgment with respect to dosage. ${ }^{1,3}$ Of these, failure is most often attributed to technical error. ${ }^{8}$ However, if failed spinal anaesthesia is repeatedly encountered in a same patient, despite following accepted methods, other causes such as anatomical abnormalities of the lumbar spine should be suspected. When such failures occur, maldistribution of the anaesthetic solution within the subarachnoid space may be more common than failure to introduce all or part of the anaesthetic solution into the subarachnoid space. Magnetic resonance imaging of the lumbar spine may assist in determining the exact anatomical characteristics. When the anaesthetic technique needs to be modified, injection at a different site will avoid repetition of the restricted distribution.

\section{References}

1 Levy $J H$, Islas $J A$, Ghia JN, Turnbull C. A retrospective study of the incidence and causes of failed spinal anesthetics in a university hospital. Anesth Analg 1985; 64: 705-10.

2 Manchikanti L, Hadley C, Markwell SJ, Colliver JA. A retrospective analysis of failed spinal anesthetic attempts in a community hospital. Anesth Analg 1987; 66: 363-6.

3 Munhall RJ, Sukhani R, Winnie AP. Incidence and etiology of failed spinal anesthetics in a university hospital: a prospective study. Anesth Analg 1988; 67: 843-8.

4 Brown DL. Spinal, epidural, and caudal anesthesia. In: Miller RD (Ed.). Anesthesia, 4th ed. New York: Churchill Livingstone Inc., 1994: 1518.

5 Abouleish $E$. How to proceed following a "failed spinal" (Letter). Anesthesiology 1992; 76: 476.

6 Greene NM. Distribution of local anesthetic solutions within the subarachnoid space. Anesth Analg 1985; 64: 715-30.

7 Hirabayashi Y, Shimizu R, Saitoh $K$, Fukuda H, Furuse $M$. Anatomical configuration of the spinal column in the supine position. I. A study using magnetic resonance imaging. Br J Anaesth 1995; 75: 3-5.

8 Drasner $K$, Rigler $M L$. Repeat injection after a "failed spinal": at times, a potentially unsafe practice. Anesthesiology 1991; 75: 713-4. 